\title{
In-Vitro Antibacterial / Antifungal Screening of 2-Chloroquinoline Scaffold Derivatives
}

\author{
Kumar $S^{* 1,3}$, Goel $N^{2}$, Afzal O ${ }^{1}$, Ali $\mathrm{MR}^{1}$ and Bawa $S^{{ }^{1}}$ \\ ${ }^{1}$ Department of Pharmaceutical Chemistry, Faculty of Pharmacy, Jamia Hamdard, New Delhi, India \\ ${ }^{2}$ Maharaja Surajmal Institute of Pharmacy, C-4, Janakpuri, New Delhi, India \\ ${ }^{3}$ Amity Institute of Pharmacy, Amity University, Noida, Uttar Pradesh, India
}

${ }^{*}$ Corresponding author: Bawa S, Department of Pharmaceutical Chemistry, Faculty of Pharmacy, Jamia Hamdard, New Delhi-110062, India, E-mail: drsbawa@rediffmail.com

Citation: Kumar S, Goel N, Afzal O, Ali MR, Bawa S (2015) In-Vitro Antibacterial / Antifungal Screening of

2-Chloroquinoline Scaffold Derivatives. J Antibiot Res 1(1): 101. doi: 10.15744/2574-5980.1.101

Received Date: December 23, 2014 Accepted Date: January 30, 2015 Published Date: February 03, 2015

\begin{abstract}
A series of differentiated 2-chloroquinoline derivatives (3-26) having various spacer groups between 2-chloroquinoline and aryl or heteroaryl ring were synthesized by chemical reactions involving nucleophilic addition, nucleophilic substitution, esterification and cyclization. All the synthesized compounds were analyzed by one or more technique such as FTIR, ${ }^{1} \mathrm{H}-\mathrm{NMR},{ }^{13} \mathrm{C}-\mathrm{NMR}$ and mass spectrometry for their structural confirmation. The derivatives were screened in-vitro for their ability to inhibit the growth of various strains of fungi and bacteria at concentration ranging from $6.25,12.5,25,50,100,200$ to $400 \mu \mathrm{g} / \mathrm{ml}$. The results of in-vitro screening unveiled that among all the compounds tested, compounds 21 showed potent antibacterial activity and its MIC was found to be in the range of $12.5 \mu \mathrm{g} / \mathrm{ml}$. In addition molecular docking studies were also performed on PDB ID (3G75) to predict the mode of action of the potent compound 21.
\end{abstract}

Keywords: Antibacterial; Antifungal; 2-chloroquinoline; Docking; Oxadiazoles

\section{Introduction}

The emergence of multi-drug resistance strains of bacteria and fungi such as Methicilin resistant Staphylococcus aureus (MRSA), Vancomycin resistant enterococcus (VRE) and Fluconazole resistant Candida species have made treatment of infectious diseases difficult and over the time have become a serious medical problem [1-5]. The mechanism of resistant is continuously evolving in pathogenic bacteria to currently used antimicrobials [6-8]. The search for new antimicrobial agents have been an important and challenging task for medicinal chemists [9-11] and discovery of novel and potent antimicrobial agents is still a best way to combat this situation [12-13].

Development new antimicrobial drug involving chemical modification of existing drugs or class of drug has come up with astound results in the field of drug discovery [14]. Some newly approved drugs or investigational drug which utilizes this strategy has allowed finding of more active and safe compounds with wide spectrum activity. Figure 1 presents some of potential investigational molecules which are in either phase II or Phase III of clinical trial derived from existing NCE's [15]. Searching for structure with propitious bioactivity we focused our attention on quinoline and its congeners which had revealed as diverse and potent antibacterial, antifungal, antimalarial, anticancer drugs antimalarial drugs and are under continuous evaluation for the development of potent bioactive molecules [16].

Some of the recent chemical modifications quinoline include Bedaquiline (R207910) which has shown extraordinary activity against both drug susceptible and drug-resistant strains of M. tuberculosis, exhibiting MIC values of 30-120 ng/ml, [17]. Laquinimod is an experimental immunomodulator drug and it is currently under investigation for oral treatment of multiple sclerosis (MS) [18]. GSK 299423 is an investigational compound which has shown potent activity against antibiotic-resistant strains of bacteria such as Staphylococus aureus, including methicillin resistance S. aureus (MRSA) and against gram-negative bacteria like E. coli, Pseudomonas, Klebsiella and Acinetobacter [19] (Figure 2). Fascinated by multifarious bioactivity of quinoline various researchers and scientists are still engaged in developing potent molecule based on quinoline such as Saeed et al. [20] have reported the synthesis of conformationally constrained Analogs of N-Substituted Piperazinylquinolones tested for antimicrobial activity. Likewise various 4-pyrazolyl-N-(hetero)arylquinoline were prepared by Nilesh et al. [21] and observed that some of the compounds were more or equipotent against most of the employed strains than commercially available drugs. Impelled by these observations and in continuation of our research for bioactive molecules based on 2-chloroquinoline system [22-24], we address here synthesis and in-vitro antimicrobial activity of some newer differentiated 2-chloroquinoline derivatives. 

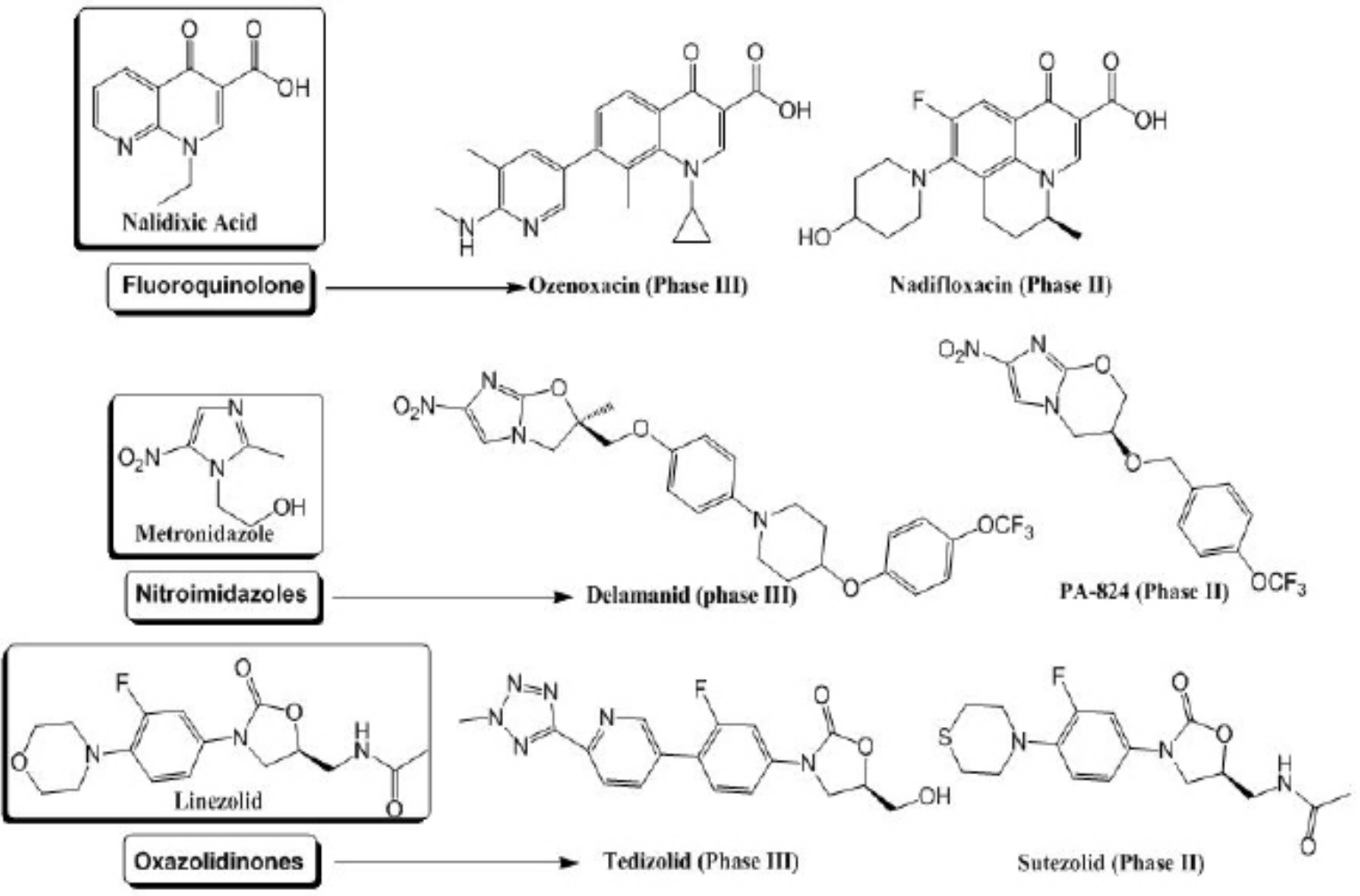

Figure 1: Chemical tailoring or chemical remodeling of existing antibacterial drugs classes, showing development of Gatifloxacin or Moxifloxacin from Nalidixic acid and investigational molecules PA-824 and OPC-67683 from Metronidazole etc<smiles>CN(C)CC[C@](Cc1ccccc1)(c1ccccc1)c1cccc2ccccc12</smiles>

Diarylqinoline (R207910)<smiles>CCN(C(=O)c1c(O)c2c(Cl)cccc2n(C)c1=O)c1ccccc1</smiles>

Laquinimod<smiles>COc1ccc2ncc(C#N)c(CCN3CCC(NCc4cc5c(cn4)OCS5)CC3)c2c1</smiles>

GSK299423

Figure 2: Chemical structures of some investigational quinoline containing antimicrobial molecules

\section{Experimental}

\section{Chemistry}

Melting points were determined by the open capillary method with electrical melting point apparatus and are uncorrected. IR spectra were recorded as $\mathrm{KBr}$ (pellet) on Bio Rad FT-IR spectrophotometer and ${ }^{1} \mathrm{H}$ and ${ }^{13} \mathrm{C}-\mathrm{NMR}$ spectra were recorded on Bruker DPX $300 \mathrm{MHz}$ spectrophotometer using DMSO- $d_{6}$ or $\mathrm{CDCl}_{3}$ as a NMR solvent. Mass spectra (MS-ESI) were recorded on a JEOL-AccuTOF JMS-T100LS mass spectrometer and elemental analysis on Vario-EL III CHNOS- Elemantar analyzer. Thin Layer Chromatography (TLC) was performed to monitor progress of the reaction and purity of the compounds, spot being located under iodine vapors or UV-light.

The starting material 2-chloro-3-formyl-quinoline 1 and 2-chloro-3-formyl-6-methylquinoline 2 were prepared according to the literature method [25].

\section{Synthesis of hydrazones (3-6)}

To a solution of 2-chloro-3-formyl-quinoline ( $0.96 \mathrm{~g}, 0.005 \mathrm{~mol}) 1$ or 2-chloro-3-formyl-6-methylquinoline $2(1.03 \mathrm{~g}, 0.005 \mathrm{~mol})$ in $20 \mathrm{ml}$ of absolute ethanol, equimolar amount of isonicotinic acid or benzoic acid hydrazide $(0.68 \mathrm{~g}, 0.005 \mathrm{~mol})$ was added and the mixture refluxed for 2-4 h. On cooling solid was obtained which was filtered, washed with hot methanol, dried and recrystallized from ethanol and DMF mixture to give final compounds. 
<smiles>[R]C(=O)N/N=C/c1cc2cc([R])ccc2nc1Cl</smiles><smiles>[AsH][AsH]</smiles><smiles>[R]c1ccc2nc(Cl)c(-c3nnc([R])o3)cc2c1</smiles><smiles>[R]c1ccc(C(=O)OCc2cc3cc([R])ccc3nc2Cl)cc1</smiles>
$(13-16)$<smiles>[R]c1ccc2nc(Cl)c(CSc3nc4cc([R])ccc4[nH]3)cc2c1</smiles>

$(23-26)$<smiles>[R]c1ccc(NCc2cc3cc([R])ccc3nc2Cl)cc1</smiles>

Figure 3: Route of synthesis of various 2-chloroquinoline derivatives compounds (3-26).Reagent and conditions: (a) INH or benzoic acid hydrazide, abs. EtOH, reflux (b) chlormine-T, ethanol/reflux (c) $\mathrm{NaBH}_{4} / \mathrm{MeOH}$, stirring (d) benzoyl chloride/p-methyl benzoyl chloride, pyridine (e) SOCl, benzene reflux (f) sulphanilamide/p-aminophenol, TEA, ethanol reflux (g) 2-mercaptobenzimidazole/ $\mathrm{NaOH}$, ethanol, reflux

$N^{\prime}$-[(2-Chloroquinolin-3-yl)methylidene]benzohydrazide 3: Yield: 82 \%; m.p.: 220-223 ${ }^{\circ} \mathrm{C}$; Anal. Calcd for $\mathrm{C}_{17} \mathrm{H}_{12} \mathrm{ClN}_{3} \mathrm{O}$; $\mathrm{C}$ 65.92; H 3.90; N 13.57 \%. Found; 65.71, H 3.93, N 13.64 \%; IR (KBr) cm ${ }^{-1}: 3260(\mathrm{~N}-\mathrm{H}), 1650(\mathrm{C}=\mathrm{O}), 1625(\mathrm{C}=\mathrm{N}), 1579(\mathrm{C}=\mathrm{C})$, $755(\mathrm{C}-\mathrm{Cl}) .{ }^{1} \mathrm{H}-\mathrm{NMR}\left(300 \mathrm{MHz}, \mathrm{DMSO}-d_{6}\right) ; \delta$ 7.54-7.63 (m, 3H, Ar-H), 7.68-7.73 (t, $\left.1 \mathrm{H}, \mathrm{H}-6, J=7.39 \mathrm{~Hz}\right), 7.85-7.90$ (t, $1 \mathrm{H}, \mathrm{H}-7$, $J=7.44 \mathrm{~Hz}), 7.95-7.99$ (m, 3H, Ar-H), 8.22-8.25 (d, $1 \mathrm{H}, \mathrm{H}-8, J=7.08 \mathrm{~Hz}), 8.82(\mathrm{~s}, 1 \mathrm{H}, \mathrm{H}-4), 8.94(\mathrm{~s}, 1 \mathrm{H}, \mathrm{CH}=\mathrm{N}), 12.22(\mathrm{~s}, 1 \mathrm{H}$, $\mathrm{CONH}) .{ }^{13} \mathrm{C}-\mathrm{NMR}\left(75 \mathrm{MHz}, \mathrm{DMSO}-d_{6}\right) ; \delta 126.1,126.8,127.6,127.7,128.5,128.9, .131 .9,133.0,135.6,142.7,147.1,148.4,157.1$, $169.2(\mathrm{C}=\mathrm{O})$.

$N^{\prime}$-[(2-Chloroquinolin-3-yl)methylidene]pyridine-4-carbohydrazide 4: Yield: $87 \%$; m.p.: $>280{ }^{\circ} \mathrm{C}$; Anal. Calcd for $\mathrm{C}_{16} \mathrm{H}_{11} \mathrm{ClN}_{4} \mathrm{O}$ : C 61.84; H 3.57; N 18.03\%. Found C 61.97, H 3.56, N $18.06 \%$; IR (KBr) cm-1 $3365(\mathrm{~N}-\mathrm{H}), 1697$ (C=O), 1629 (C=N), 1595 (C=C), $750(\mathrm{C}-\mathrm{Cl}) .{ }^{1} \mathrm{H}-\mathrm{NMR}\left(300 \mathrm{MHz}, \mathrm{DMSO}-d_{6}\right) ; \delta$ 7.66-7.71 (t, $\left.1 \mathrm{H}, \mathrm{H}-6, J=7.42 \mathrm{~Hz}\right), 7.86-7.89$ (m, 3H, Ar-H), 7.96-7.99 (d, 1H, H-5, $J=8.33 \mathrm{~Hz}), 8.19-8.22(\mathrm{~d}, 1 \mathrm{H}, \mathrm{H}-8, J=8.08 \mathrm{~Hz}), 8.80-8.84(\mathrm{~m}, 3 \mathrm{H}, \mathrm{Ar}-\mathrm{H}), 8.91(\mathrm{~s}, 1 \mathrm{H}, \mathrm{CH}=\mathrm{N}), 11.49$ (s, $1 \mathrm{H}, \mathrm{CONH})$.

$N^{\prime}$-[(2-Chloro-6-methylquinolin-3-yl)methylidene]benzohydrazide 5: Yield: 81 \%; m.p.: 190-192 ${ }^{\circ} \mathrm{C}$; Anal. Calcd for $\mathrm{C}_{18} \mathrm{H}_{14} \mathrm{ClN}_{3} \mathrm{O}$ : C 66.77; H 4.36; N $12.98 \%$. Found : C 66.51; H 4.38; N 12.94 \%; IR (KBr) cm ${ }^{-1}: 3261(\mathrm{~N}-\mathrm{H}), 1655$ (C=O), 1627 $(\mathrm{C}=\mathrm{N}), 1589(\mathrm{C}=\mathrm{C}), 759(\mathrm{C}-\mathrm{Cl}) .1 \mathrm{H}-\mathrm{NMR}\left(300 \mathrm{MHz}, \mathrm{DMSO}-d_{6}\right): \delta 2.51(\mathrm{~s}, 3 \mathrm{H}, \mathrm{CH} 3), 7.57-7.64(\mathrm{~m}, 3 \mathrm{H}, \mathrm{Ar}-\mathrm{H}), 7.70-7.73(\mathrm{~d}, 1 \mathrm{H}$, $\mathrm{H}-7, J=8.49 \mathrm{~Hz}), 7.85-7.88(\mathrm{~d}, 1 \mathrm{H}, \mathrm{H}-8, J=8.52 \mathrm{~Hz}), 7.97-8.01(\mathrm{~m}, 3 \mathrm{H}, \mathrm{Ar}-\mathrm{H}), 8.82(\mathrm{~s}, 1 \mathrm{H}, \mathrm{H}-4), 8.93(\mathrm{~s}, 1 \mathrm{H}, \mathrm{CH}=\mathrm{N}), 12.26(\mathrm{~s}, 1 \mathrm{H}$, CONH). MS (ESI) m/z: $310.09\left[\mathrm{M}^{+}\right], 312.09[\mathrm{M}+2]$.

$N^{\prime}$-[(2-Chloro-6-methylquinolin-3-yl)methylidene]pyridine-4-carbohydrazide 6: Yield: $86 \%$; m.p.: $>280{ }^{\circ} \mathrm{C}$; Anal. Calcd for $\mathrm{C}_{17} \mathrm{H}_{13} \mathrm{ClN}_{4} \mathrm{O} ; \mathrm{C} 62.87 ; \mathrm{H} 4.03 ; \mathrm{N} 17.25 \%$. Found C 62.69; H 4.01; N $17.28 \%$; IR (KBr) cm ${ }^{-1}: 3278(\mathrm{~N}-\mathrm{H}), 1673(\mathrm{C}=\mathrm{O}), 1629(\mathrm{C}=\mathrm{N})$, $1588(\mathrm{C}=\mathrm{C}), 756(\mathrm{C}-\mathrm{Cl}) .{ }^{1} \mathrm{H}-\mathrm{NMR}\left(300 \mathrm{MHz}, \mathrm{DMSO}-d_{6}\right): \delta 2.51\left(\mathrm{~s}, 3 \mathrm{H}, \mathrm{CH}_{3}\right), 7.67-7.70(\mathrm{~d}, 1 \mathrm{H}, \mathrm{H}-7, \mathrm{~J}=8.28 \mathrm{~Hz}), 7.83-7.87(\mathrm{~m}$, $3 \mathrm{H}, \mathrm{Ar}-\mathrm{H}), 7.99$ (s, 1H, H-5), 8.77-8.80 (m, 3H, Ar-H), 9.02 (s, 1H, CH=N), 11.23 (s, 1H, CONH).

\section{Synthesis of 1,3,4-Oxadiazole Derivatives (7-10)}

A mixture hydrazones (3-6) (0.001 mol), chloramines- $\mathrm{T}(1.14 \mathrm{~g}, 0.005 \mathrm{~mol})$ and $10 \mathrm{ml}$ of abs. ethanol taken in a round bottom flask and refluxed for 6-8 hr. The progress of the reaction was monitored on TLC. After word the reaction mixture was poured in water and extracted with ether. The combined extract was washed with water and dried over anhydrous sodium sulphate and concentrated under reduced pressure [26].

2-Chloro-3-[5-(pyridin-4-yl)-1,3,4-oxadiazol-2-yl] quinoline 7: Yield: 67 \%; m.p.: >300 C; Anal. Calcd for $\mathrm{C}_{16} \mathrm{H}_{9} \mathrm{ClN}_{4} \mathrm{O}$ : $\mathrm{C} 62.25$; H 2.94; N 18.15 \%. Found; C 62.49: H 2.92; N $18.21 \%$; IR (KBr) cm ${ }^{-1}: 1629$ (C=N), 1595 (C=C), 750 (C-Cl). ${ }^{1} \mathrm{H}-\mathrm{NMR}(300$ MHz, DMSO- $\left.d_{6}\right) ; \delta 7.62(\mathrm{t}, 1 \mathrm{H}, \mathrm{H}-6, J=7.2 \mathrm{~Hz}), 7.69-7.81$ (m, 2H, H-5 and H-7), 7.93-8.04 (m, 3H, Ar-H), 8.09 (s, 1H, H-4), 8.80-8.87 $(\mathrm{m}, 3 \mathrm{H}, \mathrm{Ar}-\mathrm{H}) .{ }^{13} \mathrm{C}-\mathrm{NMR}\left(75 \mathrm{MHz}, \mathrm{DMSO}-d_{6}\right) ; \delta 120.7,121.0,126.6,127.0,129.9,130.5,131.2,137.2,141.7,144.7,148.0,148.7$, 149.0, 164.5, 165.7. ESI-MS: m/z 309.12 [M+], $311.12[\mathrm{M}+2]$. 
2-Chloro-6-methyl-3-[5-(pyridin-4-yl)-1,3,4-oxadiazol-2-yl]quinoline 8: Yield: 55 \%; m.p.: > $300{ }^{\circ} \mathrm{C}$; Anal. Calcd for $\mathrm{C}_{17} \mathrm{H}_{11} \mathrm{ClN}_{4} \mathrm{O}: \mathrm{C}$ 63.26: H 3.44; N $17.36 \%$. Found: C 63.03; H 3.46; N $17.42 \%$; IR (KBr) cm ${ }^{-1}: 1629(\mathrm{C}=\mathrm{N}), 1588(\mathrm{C}=\mathrm{C}), 756(\mathrm{C}-\mathrm{Cl})$. $1 \mathrm{H}-\mathrm{NMR}\left(300 \mathrm{MHz}, \mathrm{DMSO}-d_{6}\right): \delta 2.51\left(\mathrm{~s}, 3 \mathrm{H}, \mathrm{CH}_{3}\right), 7.68(\mathrm{~d}, 1 \mathrm{H}, \mathrm{H}-7, J=8.2 \mathrm{~Hz}), 7.89-8.02(\mathrm{~m}, 3 \mathrm{H}, \mathrm{Ar}-\mathrm{H}), 8.05(\mathrm{~s}, 1 \mathrm{H}, \mathrm{H}-5)$, 8.77-8.84 (m, 3H, H-4 \& 2 x pyridine). ${ }^{13} \mathrm{C}-\mathrm{NMR}\left(75 \mathrm{MHz}\right.$, DMSO- $\left.d_{6}\right) ; \delta 20.8,121.4,122.0,126.9,128.2,130.9,131.3,133.1,135.9$, $142.9,144.2,148.3,148.6,148.9,164.7,165.4$. MS (ESI) m/z: $322.14\left[\mathrm{M}^{+}\right], 324.14$ [M+2].

2-(2-Chloroquinolin-3-yl)-5-phenyl-1,3,4-oxadiazole 9: Yield: 64 \%; m.p.: 265-267 ${ }^{\circ} \mathrm{C}$; Anal. Calcd for $\mathrm{C}_{18} \mathrm{H}_{12} \mathrm{ClN}_{3} \mathrm{O}: \mathrm{C} 66.35$; $\mathrm{H}$ 3.28; N 13.65 \%. Found: C 66.54, H 3.30, N $13.70 \%$; IR (KBr) cm ${ }^{-1}: 1637$ (C=N), 1585 (C=C), 749 (C-Cl). ${ }^{1} \mathrm{H}-\mathrm{NMR}(300 \mathrm{MHz}$, DMSO- $\left.d_{6}\right) ; \delta 7.18(\mathrm{~d}, 1 \mathrm{H}, \mathrm{Ar}-\mathrm{H}, J=7.1 \mathrm{~Hz}), 7.69-7.73(\mathrm{~m}, 2 \mathrm{H}, \mathrm{Ar}-\mathrm{H}), 7.81-7.84(\mathrm{~m}, 2 \mathrm{H}, \mathrm{Ar}-\mathrm{H}), 7.98(\mathrm{~d}, 1 \mathrm{H}, \mathrm{H}-5, J=8.3 \mathrm{~Hz}), 8.22-$ $8.26(\mathrm{~m}, 2 \mathrm{H}, \mathrm{Ar}-\mathrm{H}), 8.79(\mathrm{~s}, 1 \mathrm{H}, \mathrm{H}-4) .{ }^{13} \mathrm{C}-\mathrm{NMR}\left(75 \mathrm{MHz}, \mathrm{DMSO}-d_{6}\right) ; \delta 21.43\left(\mathrm{CH}_{3}\right), 125.88,126.36,127.93,128.08,128.74,129.13$, $131.53,133.26,134.10,135.93,143.41,146.84,148.15,159.09,165.2,165.9$.

2-(2-Chloro-6-methylquinolin-3-yl)-5-phenyl-1,3,4-oxadiazole 10: Yield: 60 \%; m.p.: 250-252 ${ }^{\circ} \mathrm{C}$; Anal. Calcd for $\mathrm{C}_{18} \mathrm{H}_{12} \mathrm{ClN}_{3} \mathrm{O}$; C 67.19, H 3.76, N 13.06. Found : C 67.43, H 3.78, N $13.11 \%$; IR (KBr) cm ${ }^{-1}: 1622(\mathrm{C}=\mathrm{N}), 1597(\mathrm{C}=\mathrm{C}), 751(\mathrm{C}-\mathrm{Cl}) .{ }^{1} \mathrm{H}-\mathrm{NMR}(300$ MHz, DMSO- $\left.d_{6}\right): \delta 7.20(\mathrm{~d}, 1 \mathrm{H}, \mathrm{Ar}-\mathrm{H}, J=7.8 \mathrm{~Hz}$ ), 7.65 (d, 1H, H-7, J= 7.4 Hz), 7.81-7.85 (m, 2H, Ar-H), 8.01 (s, $1 \mathrm{H}, \mathrm{H}-5), 8.22$ (d, $1 \mathrm{H}, \mathrm{Ar}-\mathrm{H}, J=7.3 \mathrm{~Hz}), 8.79$ (s, 1H, H-4). ESI-MS: m/z 321.17, 323.17.

\section{Synthesis of compounds 11 and 12}

To a solution of compound 1 or $2(0.01 \mathrm{~mol})$ in absolute methanol, solid sodium borohydride $(0.45 \mathrm{~g}, 0.012 \mathrm{~mol})$ was added portion wise over a period of $30 \mathrm{~min}$. with constant stirring at room temperature. After that solvent was evaporated under reduced pressure and the residue was triturated with water and the crystalline product was filtered, washed with water and dried. The product was recrystallized from methanol.

2-Chloro-3-(hydroxymethyl)-quinoline 11: Yield: 86 \%; m.p.: 160-162 ${ }^{\circ} \mathrm{C}$; Anal.Calcd for $\mathrm{C}_{10} \mathrm{H}_{8} \mathrm{ClNO}$ : C, $62.03, \mathrm{H} 4.16, \mathrm{~N} 7.23$. Found: C 62.20, H 4.14, N 7.27 \%; IR (KBr) cm ${ }^{-1}$ : $3340(\mathrm{O}-\mathrm{H}), 1614(\mathrm{C}=\mathrm{C}), 1592(\mathrm{C}=\mathrm{N}), 765(\mathrm{C}-\mathrm{Cl}) .{ }^{1} \mathrm{H}-\mathrm{NMR}(300 \mathrm{MHz}$, DMSO- $\left.d_{6}\right): \delta 4.77\left(\mathrm{~s}, 2 \mathrm{H}, \mathrm{CH}_{2}\right), 5.45\left(\mathrm{~s}, 1 \mathrm{H}, \mathrm{OH}, \mathrm{D}_{2} \mathrm{O}\right.$-exchangeble), 7.53-7.58 (t, 1H, H-6, J = 7.0 Hz), 7.67-7.72 (t, 1H, H-7, J = 6.9 $\mathrm{Hz}), 7.83-7.86(\mathrm{~d}, 1 \mathrm{H}, \mathrm{H}-5, J=7.5 \mathrm{~Hz}), 7.97-8.00(\mathrm{~d}, 1 \mathrm{H}, \mathrm{H}-8, J=8.0 \mathrm{~Hz}), 8.36(\mathrm{~s}, 1 \mathrm{H}, \mathrm{H}-4) .{ }^{13} \mathrm{C}-\mathrm{NMR}\left(\mathrm{DMSO}-d_{6}, 75 \mathrm{MHz}\right): \delta 59.9$ $\left(\mathrm{CH}_{2}\right), 126.4,127.0,127.4,127.7,129.9,133.8,135.7,146.0,148.3$. MS m/z: 194. (M). 196 (M+2).

2-Chloro-3-(hydroxymethyl)-6-methylquinoline 12: Yield: 82 \%; m.p.: 172-174 ${ }^{\circ} \mathrm{C}$; Anal. Calcd for $\mathrm{C}_{11} \mathrm{H}_{10} \mathrm{ClNO}$ : $\mathrm{C} 63.62, \mathrm{H} 4.85$, N 6.75. Found: C 63.78, H 4.86, N 6.79\%; IR (KBr) cm ${ }^{-1}$ : $3340(\mathrm{OH}), 1595(\mathrm{C}=\mathrm{N}), 1615(\mathrm{C}=\mathrm{C}), 751(\mathrm{C}-\mathrm{Cl}) .{ }^{1} \mathrm{H}-\mathrm{NMR}(300 \mathrm{MHz}$ $\left.\mathrm{CDCl}_{3}\right) \delta: 2.52\left(\mathrm{~s}, 3 \mathrm{H}, \mathrm{CH}_{3}\right), 4.66\left(\mathrm{~s}, 2 \mathrm{H}, \mathrm{CH}_{2}\right), 5.45$ (bs, 1H, OH, D O-exchangeble), 7.54- 7.57 (m, 2H, Ar- $\left.\mathrm{H}\right), 7.92(\mathrm{~d}, 1 \mathrm{H}, \mathrm{H}-8, J=$ $7.74 \mathrm{~Hz}), 8.06(\mathrm{~s}, 1 \mathrm{H}, \mathrm{H}-4) .{ }^{13} \mathrm{C}-\mathrm{NMR}\left(\mathrm{CDCl}_{3}, 75 \mathrm{MHz}\right) \delta: 18.94\left(\mathrm{CH}_{3}\right), 57.8\left(\mathrm{CH}_{2}\right), 126.1,126.9,127.8,130.5,131.9,135.4,142.0$, 148.0. MS m/z: $208\left(\mathrm{M}^{+}\right), 210(\mathrm{M}+2)$.

\section{General method for the synthesis of compounds (13-16)}

To a solution of 11 or $12(0.005 \mathrm{~mol})$ in pyridine $(10.0 \mathrm{~mL})$ was slowly added benzoyl chloride $(0.7 \mathrm{~g}, 0.005 \mathrm{~mol})$ or p-tuloloyl chloride $(0.77 \mathrm{~g}, 0.005 \mathrm{~mol})$ at room temperature. After stirring for $10 \mathrm{~min}$, the mixture was allowed to warm at room temperature and maintained for $2 \mathrm{~h}$. The mixture was then diluted with cold water $(50 \mathrm{~mL})$, the solid product obtained was washed repeatedly to remove pyridine. The dried product was than recrystallized from ethanol.

(2-chloroquinolin-3-yl) methyl benzoate 13: Yield: 88 \%; m.p.: 135-137 ${ }^{\circ} \mathrm{C}$; Anal. Calcd for $\mathrm{C}_{17} \mathrm{H}_{12} \mathrm{ClNO}_{2}$ : $\mathrm{C}, 68.58$; $\mathrm{H}, 4.06$; N, $4.70 \%$ Found : C, 68.58; H, 4.06; N, $4.70 \%$; IR (KBr) cm ${ }^{-1}: 1728(\mathrm{C}=\mathrm{O}), 1620(\mathrm{C}=\mathrm{C}), 1595(\mathrm{C}=\mathrm{N}), 1120$ (C-O), $754(\mathrm{C}-\mathrm{Cl})$. ${ }^{1} \mathrm{H}-\mathrm{NMR}\left(300 \mathrm{MHz}, \mathrm{CDCl}_{3}\right): \delta 5.06$ (s, 2H, CH2), 7.34-7.42 (m, 3H, Ar-H), 7.48-7.55 (m, 3H, Ar-H), 7.69-7.77 (m, 2H, Ar-H), $8.01(\mathrm{~d}, 1 \mathrm{H}, \mathrm{H}-8, J=7.8 \mathrm{~Hz}), 8.14(\mathrm{~s}, 1 \mathrm{H}, \mathrm{H}-4) .{ }^{13} \mathrm{C}-\mathrm{NMR}\left(\mathrm{CDCl}_{3}, 75 \mathrm{MHz}\right): \delta 64.6\left(\mathrm{CH}_{2} \mathrm{O}-\right), 125.9,127.2,127.6,128.7,129.0,129.5$, $130.1,131.4,132.8,136.3,146.0,152.2,169.2$ (C=O). MS (ESI) m/z: $297.12\left[\mathrm{M}^{+}\right] 299.12[\mathrm{M}+2]$.

(2-chloroquinolin-3-yl) methyl 4-methylbenzoate 14: Yield: 88 \%; m.p.: 170-171 ${ }^{\circ} \mathrm{C}$; Anal. Calcd for $\mathrm{C}_{18} \mathrm{H}_{14} \mathrm{ClNO}_{2}$ : C, 69.35; $\mathrm{H}$, 4.53; N, $4.49 \%$. Found; C, 69.16; H, 4.55; N, $4.52 \%$. IR (KBr) cm ${ }^{-1}: 1724(\mathrm{C}=\mathrm{O}), 1613(\mathrm{C}=\mathrm{C}), 1590(\mathrm{C}=\mathrm{N}), 1118(\mathrm{C}-\mathrm{O}), 758(\mathrm{C}-\mathrm{Cl})$. ${ }^{1} \mathrm{H}-\mathrm{NMR}\left(300 \mathrm{MHz}, \mathrm{CDCl}_{3}\right): \delta 2.26\left(\mathrm{~s}, 3 \mathrm{H}, \mathrm{CH}_{3}\right), 5.02\left(\mathrm{~s}, 2 \mathrm{H}, \mathrm{CH}_{2}\right), 7.22(\mathrm{~d}, 2 \mathrm{H}, \mathrm{H}-3$ ' \& 5', J = 7.0 Hz), 7.51-7.58 (m, $3 \mathrm{H}, \mathrm{Ar}-\mathrm{H})$, 7.71-7.79 (m, 2H, Ar-H), 8.03 (d, 1H, H-8, J = 7.4 Hz ), $8.10(\mathrm{~s}, 1 \mathrm{H}, \mathrm{H}-4) .13 \mathrm{C}-\mathrm{NMR}\left(75 \mathrm{MHz}, \mathrm{CDCl}_{3}\right) \delta: 21.4\left(\mathrm{CH}_{3}\right), 64.4\left(\mathrm{CH}_{2} \mathrm{O}\right)$, $124.8,126.4,127.1,127.0,128.6,129.7,130.2,130.8,131.5,135.8,137.1,143.9,150.4,169.4$.

(2-chloro-6-methylquinolin-3-yl) methyl benzoate 15: Yield: 88 \%; m.p.: 166-167 ${ }^{\circ} \mathrm{C}$; Anal. Calcd for $\mathrm{C}_{18} \mathrm{H}_{14} \mathrm{ClN} 2 \mathrm{O}$ : $\mathrm{C}, 69.35$; $\mathrm{H}$, 4.53; N, 4.49. Found:C, 69.59; H, 4.55; N, $4.53 \%$; IR (KBr) cm ${ }^{-1}: 1726(\mathrm{C}=\mathrm{O}), 1627(\mathrm{C}=\mathrm{C}), 1597(\mathrm{C}=\mathrm{N}), 1123(\mathrm{C}-\mathrm{O}), 754(\mathrm{C}-\mathrm{Cl})$.

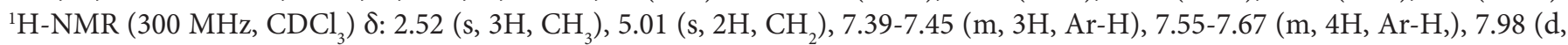
$1 \mathrm{H}, \mathrm{H}-8, J=7.6 \mathrm{~Hz}), 8.09$ (s, 1H, H-4). ${ }^{13} \mathrm{C}-\mathrm{NMR}\left(75 \mathrm{MHz}, \mathrm{CDCl}_{3}\right)$ ) $: 18.9\left(\mathrm{CH}_{3}\right), 64.7\left(\mathrm{CH}_{2} \mathrm{O}\right), 125.2,126.5,127.2,127.8,128.4$, $129.5,130.1,130.6,132.1,136.8,138.0,143.9,151.4,169.7 . \mathrm{MS}(\mathrm{ESI}) \mathrm{m} / \mathrm{z} ; 311.08\left[\mathrm{M}^{+}\right], 313.08[\mathrm{M}+2]$.

(2-chloro-6-methylquinolin-3-yl) methyl 4-methylbenzoate 16: Yield: 88 \%; m.p.: 189-191 ${ }^{\circ} \mathrm{C}$; Anal. Calcd for $\mathrm{C}_{19} \mathrm{H}_{16} \mathrm{ClN}_{2} \mathrm{O}: \mathrm{C}_{\text {, }}$ 70.05; H, 4.95; N, 4.30 Found C, 70.23; H, 4.97; N, $4.25 \%$. IR (KBr) cm ${ }^{-1}: 1730(\mathrm{C}=\mathrm{O}), 1613(\mathrm{C}=\mathrm{C}), 1590(\mathrm{C}=\mathrm{N}), 1117(\mathrm{C}-\mathrm{O}), 758$ $(\mathrm{C}-\mathrm{Cl}) .{ }^{1} \mathrm{H}-\mathrm{NMR}\left(300 \mathrm{MHz}, \mathrm{CDCl}_{3}\right) \delta: 2.27\left(\mathrm{~s}, 3 \mathrm{H}, \mathrm{Ph}-\mathrm{CH}_{3}\right), 2.51\left(\mathrm{~s}, 3 \mathrm{H}, \mathrm{CH}_{3}\right), 5.03\left(\mathrm{~s}, 2 \mathrm{H}, \mathrm{CH}_{2}\right), 7.25\left(\mathrm{~d}, 2 \mathrm{H}, \mathrm{H}-3^{\prime}\right.$ \& 5', J = 7.2 Hz), 7.52-7.61 (m, 4H, Ar-H,), 7.97 (d, 1H, H-8, J = 8.0 Hz), 8.09 (s, 1H, H-4).13C-NMR (75 MHz, CDCl $)$ ): $18.7\left(\mathrm{CH}_{3}\right), 21.4\left(\mathrm{CH}_{3}\right)$, $64.9\left(\mathrm{CH}_{2} \mathrm{O}\right), 112.9,118.0,126.3,127.3,127.7,129.3,130.4,132.2,135.9,137.0,145.3,147.1,148.8$. 


\section{Synthesis of chloromethyl derivatives $(17,18)$}

To a solution of compound 11 or $12(0.01 \mathrm{~mol})$ in dry benzene, $\mathrm{SOCl}_{2}(1.55 \mathrm{~g}, 0.013 \mathrm{~mol})$ was added and the mixture refluxed for $4 \mathrm{hr}$. Solvent was evaporated under reduced pressure and the residue was dissolved in ether, washed with $10 \% \mathrm{NaHCO}_{3}$ and twice with water. Dried over $\mathrm{Na}_{2} \mathrm{SO}_{4}$ and concentrated in vacuvo to give a residue which was crystallized from methanol.

3-(chloromethyl)-2-chloroquinoline 17: Yield: 83 \%; m.p.: $116{ }^{\circ} \mathrm{C}$; Yield 80\%; mp. $116{ }^{\circ} \mathrm{C}$; Anal.Calcd for $\mathrm{C}_{10} \mathrm{H}_{7} \mathrm{Cl}_{2} \mathrm{~N}$ : $\mathrm{C}, 56.63$, $\mathrm{H}, 3.33$; N, 6.60. Found: C, 56.46; H, 3.31; N, $6.63 \%$; IR (KBr) cm ${ }^{-1}: 1620(\mathrm{C}=\mathrm{C}), 1590(\mathrm{C}=\mathrm{N}), 754(\mathrm{C}-\mathrm{Cl}) .{ }^{1} \mathrm{H}-\mathrm{NMR}(300 \mathrm{MHz}$, $\left.\mathrm{CDCl}_{3}\right): \delta 4.82\left(\mathrm{~s}, 2 \mathrm{H}, \mathrm{CH}_{2}\right), 7.54-7.59(\mathrm{t}, 1 \mathrm{H}, \mathrm{H}-6, J=7.2 \mathrm{~Hz}), 7.71-7.76(\mathrm{t}, 1 \mathrm{H}, \mathrm{H}-7, J=7.5 \mathrm{~Hz}), 7.81-7.83(\mathrm{~d}, 1 \mathrm{H}, \mathrm{H}-5, J=7.9 \mathrm{~Hz})$, 8.00-8.03 (d,1H, H-8, J = 8.3 Hz), 8.26 (s, 1H, H-4). ${ }^{13} \mathrm{C}-\mathrm{NMR}\left(\mathrm{CDCl}_{3}, 75 \mathrm{MHz}\right): \delta 43.03\left(\mathrm{CH}_{2}\right), 126.91,127.38,127.45,128.12$, $128.89,130.87,138.60,147.12,149.51$. MS: $m / z 212\left(\mathrm{M}^{+}\right), 214(\mathrm{M}+2)$.

2-Chloro-3-(chloromethyl)-6-methylquinoline 18: Yield: $88 \%$; m.p.: $140{ }^{\circ} \mathrm{C}$; Yield 85 \%, m.p. $140{ }^{\circ} \mathrm{C}$; $\mathrm{Anal} \mathrm{Calcd}_{\text {for }} \mathrm{C}_{11} \mathrm{H}_{9} \mathrm{Cl}_{2} \mathrm{~N}$ : C, 58.43; H, 4.01; N, 6.19. Found: C, 58.30; H, 4.03; N, 6.22 \%; IR (KBr) cm ${ }^{-1}: 1620(\mathrm{C}=\mathrm{C}), 1595(\mathrm{C}=\mathrm{N}), 759(\mathrm{C}-\mathrm{Cl}),{ }^{1} \mathrm{H}-\mathrm{NMR}$

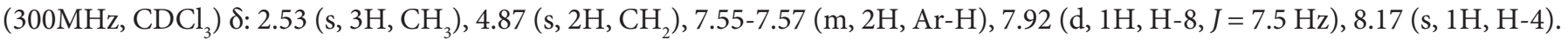

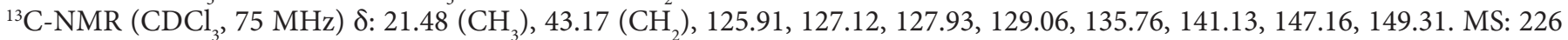
$\left(\mathrm{M}^{+}\right), 228(\mathrm{M}+2)$.

\section{Synthesis of compounds 19-22}

To a mixture of compound $3(0.003 \mathrm{~mol})$ and sulphanilamide/ p-aminophenol $(0.003 \mathrm{~mol})$ in $20 \mathrm{~mL}$ of absolute ethanol, $1 \mathrm{~mL}$ of triethylamine (TEA) was added and refluxed for 12-15 h. After completion of the reaction, content of the flask reduced to half and left overnight. The crystalline mass obtained was filtered off, washed with water, dried and recrystallized from ethanol to give $19-22$.

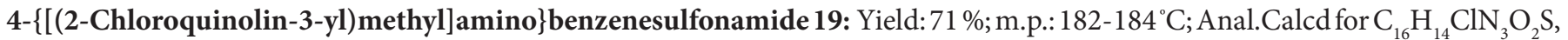
C,55.25; H, 4.06; N, 12.08. Found: C, 55.41; H, 4.07; N, $12.13 \%$; IR (KBr) cm ${ }^{-1}: 3298(\mathrm{~N}-\mathrm{H}), 1619(\mathrm{C}=\mathrm{C}), 1599(\mathrm{C}=\mathrm{N}), 1340(\mathrm{~S}=\mathrm{O})$, 1029 (C-N), $736(\mathrm{C}-\mathrm{Cl}) .{ }^{1} \mathrm{H}-\mathrm{NMR}\left(300 \mathrm{MHz}_{\mathrm{CDCl}}\right): \delta 4.37$ (bs, $1 \mathrm{H}, \mathrm{NH}, \mathrm{D}$ - O-exchangeble), $4.60(\mathrm{~s}, 2 \mathrm{H}, \mathrm{CH}), 6.65$ (d, $2 \mathrm{H}, \mathrm{H}-2$ ' \& 6', $J=8.0 \mathrm{~Hz}), 6.82\left(\mathrm{bs}, 2 \mathrm{H}, \mathrm{SO}_{2} \mathrm{NH}_{2}\right), 7.15\left(\mathrm{~d}, 2 \mathrm{H}, \mathrm{H}-3^{\prime} \&\right.$ \& $\left.5^{\prime} J=7.8 \mathrm{~Hz}\right), 7.55(\mathrm{t}, 1 \mathrm{H}, \mathrm{H}-6, J=7.4 \mathrm{~Hz}), 7.67-7.76(\mathrm{~m}, 2 \mathrm{H}, \mathrm{Ar}-\mathrm{H})$, $8.03(\mathrm{~d}, 1 \mathrm{H}, \mathrm{H}-8, J=8.2 \mathrm{~Hz}), 8.10(\mathrm{~s}, 1 \mathrm{H}, \mathrm{H}-4) .{ }^{13} \mathrm{C}-\mathrm{NMR}\left(\mathrm{CDCl}_{3}, 75 \mathrm{MHz}\right): \delta 43.1\left(\mathrm{CH}_{2}\right), 112.4,112.6,125.9,126.7,127.2,127.9$, $128.2,129.3,129.8,131.3,132.0,146.0,151.5,152.8$. MS (ESI) $\mathrm{m} / \mathrm{z}: 347.11\left[\mathrm{M}^{+}\right], 349.11[\mathrm{M}+2]$.

4-\{[(2-Chloro-6-methylquinolin-3-yl)methyl]amino\}benzenesulfonamide 20: Yield: 66 \%; m.p.: 201-203 ${ }^{\circ} \mathrm{C}$; Anal. Calcd for $\mathrm{C}_{17} \mathrm{H}_{16} \mathrm{ClN}_{3} \mathrm{O}_{2} \mathrm{~S}$ : C, 56.43; H, 4.46; N, 11.61. Found:C, 56.26; H, 4.48; N, $11.68 \%$; IR (KBr) cm c $^{-1} 3290(\mathrm{~N}-\mathrm{H}), 1619(\mathrm{C}=\mathrm{C}), 1589$ $(\mathrm{C}=\mathrm{N}), 1337(\mathrm{~S}=\mathrm{O}), 1028(\mathrm{C}-\mathrm{N}), 742(\mathrm{C}-\mathrm{Cl}) .{ }^{1} \mathrm{H}-\mathrm{NMR}\left(300 \mathrm{MHz}, \mathrm{CDCl}_{3}\right) \delta: 2.52\left(\mathrm{~s}, 3 \mathrm{H}, \mathrm{CH}_{3}\right), 4.30\left(\mathrm{~s}, 1 \mathrm{H}, \mathrm{NH}, \mathrm{D}_{2} \mathrm{O}-\right.$ exchangeble), $4.62\left(\mathrm{~s}, 2 \mathrm{H}, \mathrm{CH}_{2}\right), 6.70$ (d, 2H, H-2'\& 6', J = 7.8 Hz), 6.84(bs, 2H, $\mathrm{SO}_{2} \mathrm{NH}_{2} 7.17$ (d, 2H, H-3' \& 5', J = 7.3 Hz), 7.57-7.66 (m, $2 \mathrm{H}, \mathrm{H}-5$ \& H-7), $7.95(\mathrm{~d}, 1 \mathrm{H}, \mathrm{H}-8, J=7.8 \mathrm{~Hz}), 8.10(\mathrm{~s}, 1 \mathrm{H}, \mathrm{H}-4) .361,363$

4-((2-Chloroquinolin-3-yl)methyl)amino)phenol 21: Yield: 62 \%; m.p.: 221-223 ${ }^{\circ} \mathrm{C}$; Anal. Calcd for $\mathrm{C}_{16} \mathrm{H}_{13} \mathrm{ClN}_{2} \mathrm{O}$ : $\mathrm{C}, 67.49$; $\mathrm{H}_{\text {, }}$ 4.60; N, 9.84.Found: C, 67.66; H, 4.62; N, $9.89 \%$; IR (KBr) cm ${ }^{-1}: 3387(\mathrm{~N}-\mathrm{H}), 3452(\mathrm{O}-\mathrm{H}) 1633(\mathrm{C}=\mathrm{C}), 1593(\mathrm{C}=\mathrm{N}), 1040$ (C-N), $752(\mathrm{C}-\mathrm{Cl}) .{ }^{1} \mathrm{H}-\mathrm{NMR}\left(300 \mathrm{MHz}, \mathrm{CDCl}_{3}\right): \delta 4.35$ (s, 1H, NH, D O-exchangeble), 4.59 (s, 2H, $\left.\mathrm{CH}_{2}\right), 6.62(\mathrm{~d}, 2 \mathrm{H}, \mathrm{H}-2$ ' \& 6', J = 7.6 $\mathrm{Hz}), 6.89$ (H-3' \& 5', J = 7.8 Hz), 7.53-7.57 (t, 1H, H-6, J = 7.4 Hz), 7.71-7.79 (m, 2H, H-5 and H-7), 8.07 (d, 1H, H-8, J = 8.0 Hz), $8.11(\mathrm{~s}, 1 \mathrm{H}, \mathrm{H}-4), 11.52(\mathrm{~s}, 1 \mathrm{H}, \mathrm{OH}) \cdot{ }^{13} \mathrm{C}-\mathrm{NMR}\left(\mathrm{CDCl}_{3}, 75 \mathrm{MHz}\right): \delta 44.4\left(\mathrm{CH}_{2}\right), 115.8,116.2,116.8,126.6,126.9,127.35,127.8$, $129.5,130.8,135.7,142.5,146.2,147.2,152.0$. MS (ESI) m/z: 284.14 [M+ $\mathrm{M}^{+}, 286.14[\mathrm{M}+2]$.

4-((2-Chloro-6-methylquinolin-3-yl)methylamino)phenol 22: Yield: 68 \%; m.p.: $254{ }^{\circ} \mathrm{C}$; Anal. Calcd for $\mathrm{C}_{17} \mathrm{H}_{15} \mathrm{ClN}_{2} \mathrm{O}: \mathrm{C}$, 68.34 ; H, 5.06; N, 9.38. Found:C, 68.56; H, 5.07; N, $9.44 \%$. IR (KBr) cm c $^{-1} 3408(\mathrm{~N}-\mathrm{H}), 3459(\mathrm{O}-\mathrm{H}), 1632(\mathrm{C}=\mathrm{C}), 1598(\mathrm{C}=\mathrm{N}), 1040$ $(\mathrm{C}-\mathrm{N}), 752(\mathrm{C}-\mathrm{Cl}) .{ }^{1} \mathrm{H}-\mathrm{NMR}\left(300 \mathrm{MHz} \mathrm{CDCl}_{3}\right) \delta: 2.52\left(\mathrm{~s}, 3 \mathrm{H}, \mathrm{CH}_{3}\right), 4.38\left(\mathrm{~s}, 1 \mathrm{H}, \mathrm{NH}, \mathrm{D}_{2} \mathrm{O}\right.$-exchangeble), $4.62\left(\mathrm{~s}, 2 \mathrm{H}, \mathrm{CH}_{2}\right), 6.66$ (d, 2H, H-2' \& 6', J = 7.4 Hz), 6.91 (d, 2H, H-3' \& 5'J = 7.6), 7.99 (d, 1H, H-8, J = 7.5 Hz), 8.10 (s, 1H, H-4) 11.62 (s, 1H, OH).

\section{Synthesis of compounds 23-26}

Sodium hydroxide $(0.132 \mathrm{~g}, 0.0033 \mathrm{~mol})$ was slowly added over $5 \mathrm{~min}$ to a stirred solution of 2-mercaptobenzimidazole $(0.21 \mathrm{~g}$, $0.0014 \mathrm{~mol})$ or 6-nitro-2-mercaptobenzimidazole $(0.28 \mathrm{~g}, 0.0014 \mathrm{~mol})$ in ethanol $(20 \mathrm{~mL})$. Compound $17 \mathrm{or} 18$ (0.0016 mol) was slowly added to this solution at $0^{\circ} \mathrm{C}$ and stirred for $12-14 \mathrm{hrs}$ at room temperature. The completion of the reaction was monitored on TLC and after that solvent was removed under reduced pressure, the residue was poured into $10 \% \mathrm{NaHCO}_{3}$ solution and extracted with ethyl acetate. The organic layer was dried over $\mathrm{Na}_{2} \mathrm{SO}_{4}$, and concentrated. The residue was crystallized from methanol [27].

3-[(1H-benzimidazol-2-ylsulfanyl)methyl]-2-chloroquinoline 23: Yield: 73 \%; m.p.: 211-213 ${ }^{\circ} \mathrm{C}$; Anal. Calcd for $\mathrm{C}_{17} \mathrm{H}_{12} \mathrm{ClN}_{3} \mathrm{~S}$; $\mathrm{C}$, 62.67; H, 3.71; N, 12.90. Found:C, 62.78; H, 3.73; N, $12.97 \%$. IR (KBr) cm ${ }^{-1}: 1625(\mathrm{C}=\mathrm{C}), 1599(\mathrm{C}=\mathrm{N}), 1091(\mathrm{C}-\mathrm{S}-\mathrm{C}), 757$ (C-Cl). ${ }^{1} \mathrm{H}-\mathrm{NMR}\left(300 \mathrm{MHz}, \mathrm{CDCl}_{3}\right): \delta 4.69\left(\mathrm{~s}, 2 \mathrm{H}, \mathrm{CH}_{2}\right), 7.27-7.30(\mathrm{~m}, 2 \mathrm{H}, \mathrm{Ar}-\mathrm{H}), 7.52-7.60$ (m, 3H, Ar-H), 7.69-7.76 (m, $2 \mathrm{H}, \mathrm{H}-7$ and 5), $8.03(\mathrm{~d}, 1 \mathrm{H}, \mathrm{H}-8, J=8.3 \mathrm{~Hz}), 8.13(\mathrm{~s}, 1 \mathrm{H}, \mathrm{H}-4) .{ }^{13} \mathrm{C}-\mathrm{NMR}\left(\mathrm{CDCl}_{3}, 75 \mathrm{MHz}\right): \delta 38.0\left(\mathrm{CH}_{2}\right), 116.1,116.8,124.8,125.0,126.6,127.2$, 127.7, 128.1, 129.3, 131.2, 137.9, 138.3, 145.6, 148.4, 151.0. MS (ESI) m/z: 325.10 [M+1 327.10 [M+2]. 
2-Chloro-3-\{[(6-nitro-1H-benzimidazol-2-yl)sulfanyl $]$ methyl $\}$ quinoline 24: Yield: 60 \%; m.p.: 238-240 ${ }^{\circ} \mathrm{C}$; Anal. Calcd for $\mathrm{C}_{17} \mathrm{H}_{11} \mathrm{ClN}_{4} \mathrm{O}_{2} \mathrm{~S} ; \mathrm{C}, 55.06 ; \mathrm{H}, 2.99 ; \mathrm{N}, 15.11$. Found:C, 55.27; H, 2.97; N, $15.19 \%$; IR (KBr) cm ${ }^{-1}: 1630(\mathrm{C}=\mathrm{C}), 1590(\mathrm{C}=\mathrm{N}), 1088$ (C-S-C), $751(\mathrm{C}-\mathrm{Cl}) .{ }^{1} \mathrm{H}-\mathrm{NMR}\left(300 \mathrm{MHz}, \mathrm{CDCl}_{3}\right) \delta: 2.51\left(\mathrm{~s}, 3 \mathrm{H}, \mathrm{CH}_{3}\right), 4.70\left(\mathrm{~s}, 2 \mathrm{H}, \mathrm{CH}_{2} \mathrm{~S}\right), 7.25-7.28$ (m, 2H, Ar-H), $7.58-7.67$ (m, $4 \mathrm{H}, \mathrm{Ar}-\mathrm{H}), 7.98(\mathrm{~d}, 1 \mathrm{H}, \mathrm{H}-8, J=7.8 \mathrm{~Hz}), 8.10(\mathrm{~s}, 1 \mathrm{H}, \mathrm{H}-4) \cdot{ }^{13} \mathrm{C}-\mathrm{NMR}\left(\mathrm{CDCl}_{3}, 75 \mathrm{MHz}\right): \delta 38.3\left(\mathrm{CH}_{2}\right), 113.2,115.7,118.5,125.8$, $126.2,126.7,127.5,129.3,131.1,136.7,139.0,144.7,145.3,150.0,152.3$.

3-[(1H-benzimidazol-2-ylsulfanyl)methyl]-2-chloro-6-methylquinoline 25: Yield: 64 \%; m.p.: 196-198 ${ }^{\circ} \mathrm{C}$; Anal. Calcd for $\mathrm{C}_{18} \mathrm{H}_{14} \mathrm{ClN}_{3} \mathrm{~S}$; C, 63.62; H, 4.15; N, 12.36. Found: C, 63.51; H, 4.17; N, $12.43 \%$; IR (KBr) cm ${ }^{-1}: 1631(\mathrm{C}=\mathrm{C}), 1594(\mathrm{C}=\mathrm{N}), 1095$ $(\mathrm{C}-\mathrm{S}-\mathrm{C}), 752(\mathrm{C}-\mathrm{Cl}) .{ }^{1} \mathrm{H}-\mathrm{NMR}\left(300 \mathrm{MHz}, \mathrm{CDCl}_{3}\right): \delta 4.72\left(\mathrm{~s}, 2 \mathrm{H}, \mathrm{CH}_{2}\right), 7.21-7.23(\mathrm{~d}, 1 \mathrm{H}, \mathrm{Ar}-\mathrm{H}, J=7.3 \mathrm{~Hz}), 7.57-7.62(\mathrm{~m}, 3 \mathrm{H}, \mathrm{Ar}-$ $\mathrm{H}), 7.67-7.75$ (m, 2H, H-7 and 5), 8.05 (d,1H, H-8, J = 8.0 Hz), 8.10 (s, 1H, H-4).

2-Chloro-6-methyl-3-\{[(6-nitro-1H-benzimidazol-2-yl)sulfanyl]methyl\}quinoline 26: Yield: 59 \%; m.p.: 209-211 ${ }^{\circ} \mathrm{C}$; Anal. Calcd for $\mathrm{C}_{18} \mathrm{H}_{13} \mathrm{ClN}_{4} \mathrm{O}_{2} \mathrm{~S} ; \mathrm{C}, 56.18 ; \mathrm{H}, 3.40 ; \mathrm{N}, 14.56$. Found:C, 56.42; H, 3.41; N, $14.61 \%$; IR (KBr) cm ${ }^{-1}: 1620(\mathrm{C}=\mathrm{C}), 1589(\mathrm{C}=\mathrm{N})$, $1093(\mathrm{C}-\mathrm{S}-\mathrm{C}), 750(\mathrm{C}-\mathrm{Cl}) .{ }^{1} \mathrm{H}-\mathrm{NMR}\left(300 \mathrm{MHz}, \mathrm{CDCl}_{3}\right) \delta: 2.52\left(\mathrm{~s}, 3 \mathrm{H}, \mathrm{CH}_{3}\right), 4.70\left(\mathrm{~s}, 2 \mathrm{H}, \mathrm{CH}_{2} \mathrm{~S}\right), 7.19-7.21$ (d, $\left.1 \mathrm{H}, \mathrm{Ar}-\mathrm{H}, J=7.5 \mathrm{~Hz}\right)$, 7.57-7.69 (m, 4H, Ar-H), 8.01 (d, 1H, H-8, J= 7.2 Hz), 8.08 (s, 1H, H-4).

\section{Antimicrobial Screening}

The newly synthesized compounds (3-26) were tested against a panel of bacterial strains such as Escherichia coli (NCTC, 10418), Staphylococcus aureus (NCTC, 65710), Pseudomonas aeruginosa (NCTC, 10662) and fungal strains viz. Aspergillus niger (MTCC, 281), Aspergillus flavus (MTCC, 277), Monascus purpureus (MTCC, 369), Penicillium citrinum (NCIM, 768) by cup-plate method. Potato dextrose agar (PDA) and nutrient agar were used as culture medium for antifungal and antibacterial activity respectively. Normal saline with tween $80(0.01 \%)$ was used to make suspension of fungal and bacterial spore for lawning. Fifty milliliters of PDA medium was poured into each petri dish $(15 \mathrm{~cm}$ diameter). Five $\mathrm{ml}$ of the spore suspension was spread over the solid agar medium and plates were dried in incubator at $37^{\circ}$ for $1 \mathrm{hr}$. Using an agar punch, wells were made on these seeded agar plates and solutions of test compounds in DMSO at conc. range of 6.25, 12.5, 25.0, 50, 100 and $200 \mu \mathrm{g} / \mathrm{ml}$ were added into each well, labeled previously. A control was also prepared using solvent DMSO. The Petri plate were prepared in duplicate and incubated at $30{ }^{\circ} \mathrm{C}$ for $72 \mathrm{hr}$ for fungi and $37^{\circ} \mathrm{C}$ for $24 \mathrm{hr}$ for bacteria. Antifungal activity was determined by measuring zone of inhibition and the minimum inhibitory concentration (MIC) was noted by seeing the lowest concentration of the test drug at which there was no visible growth. Activity of each compound (3-26) was compared with standard Fluconazole and Ciprofloxacin and results have been summarized as MIC (average zone of inhibition of two reading in millimeter) in Table 1.

\section{Computational Studies}

The crystal structure of bacterial DNA gyrase (PDB code: 3G75, Resolution-2.30 Å)was retrieved from Protein Data Bank (PDB) and was utilized for molecular docking studies .Protein was prepared with the Protein Preparation Wizard in Maestro using options: bond orders were assigned, hydrogen atoms were added, formal charges were treated and water molecules were deleted. Hydrogen bonding network was then optimized using the exhaustive sampling option and the protein was minimized to an RMSD limit from the starting structure of $0.3 \AA$ using the Impref module of Impact with the OPLS_2005 force field. Prepared protein structure was used to generate Glide scoring grids for the subsequent docking calculations. Docking grids was generated with the default settings in Glide using the co-crystalized ligand (B48)to define the centre of the grid box $(20 \times 20 \times 20 \AA)$. Default parameters were used and no constraints were included during grid generation. The three dimensional coordinates of the most potent compound 21 was generated using Maestro module of Schrodinger. Ligands were prepared using LigPrep 2.6 with Epik 2.4 to expand protonation and tautomeric states at $7.0 \pm 2.0 \mathrm{pH}$ units and energy was minimized using the OPLS 2005 force field. The docking calculations were performed by Glide XP docking.

\begin{tabular}{|c|c|c|c|c|c|c|c|c|}
\hline \multirow{2}{*}{$\begin{array}{c}\text { Compd. } \\
\text { No }\end{array}$} & \multirow{2}{*}{$\mathbf{R}$} & \multirow{2}{*}{$\mathbf{R}^{1} / \mathbf{R}^{2} / \mathbf{R}^{3}$} & \multicolumn{5}{|c|}{ MIC (zone of inhibition in mm) } \\
\cline { 4 - 9 } & & & \multicolumn{4}{|c|}{ Antibacterial activity } & \multicolumn{2}{|c|}{ Antifungal activity } \\
\cline { 4 - 9 } & & & E. coli & S. aureus & P. aurogiosa & C albican & A.flavus & A. niger \\
\hline $\mathbf{3}$ & $\mathrm{H}$ & 4 -Pyridinyl & $25(6.5)$ & $50(7.5)$ & $50(6.5)$ & $200(6.0)$ & $100(6.5)$ & $100(7.5)$ \\
\hline $\mathbf{4}$ & $\mathrm{H}$ & Phenyl & $100(7.5)$ & $200(6.5)$ & $200(5.5)$ & $200(6.5)$ & $200(7.0)$ & $200(5.5)$ \\
\hline $\mathbf{5}$ & $\mathrm{CH}_{3}$ & 4 -Pyridinyl & $25(6.5)$ & $50(8.0)$ & $50(5.0)$ & $200(7.0)$ & $100(7.0)$ & $100(6.5)$ \\
\hline $\mathbf{6}$ & $\mathrm{CH}_{3}$ & Phenyl & $100(6.5)$ & $200(7.5)$ & $200(6.5)$ & $200(7.5)$ & $200(7.0)$ & $200(8.5)$ \\
\hline $\mathbf{7}$ & $\mathrm{H}$ & 4 -Pyridinyl & $12.5(6.0)$ & $25(7.5)$ & $50(6.0)$ & $100(6.0)$ & $100(6.5)$ & $50(5.0)$ \\
\hline $\mathbf{8}$ & $\mathrm{CH}_{3}$ & 4 -Pyridinyl & $12.5(6.5)$ & $25(8.0)$ & $50(7.0)$ & $100(6.5)$ & $100(7.0)$ & $100(7.5)$ \\
\hline $\mathbf{9}$ & $\mathrm{H}$ & Phenyl & $100(7.5)$ & $200(7.5)$ & $200(8.0)$ & $100(7.0)$ & $100(7.0)$ & $100(6.5)$ \\
\hline $\mathbf{1 0}$ & $\mathrm{CH}_{3}$ & Phenyl & $50(5.5)$ & $200(8.5)$ & $200(7.0)$ & $100(7.5)$ & $100(7.5)$ & $100(7.5)$ \\
\hline $\mathbf{1 1}$ & $\mathrm{H}$ & - & $50(6.5)$ & $100(5.5)$ & $100(5.5)$ & $200(6.0)$ & $200(6.5)$ & $200(5.8)$ \\
\hline $\mathbf{1 2}$ & $\mathrm{CH}_{3}$ & - & $50(5.8)$ & $100(5.5)$ & $100(5.5)$ & $200(6.5)$ & $100(7.0)$ & $100(5.5)$ \\
\hline $\mathbf{1 3}$ & $\mathrm{H}$ & $\mathrm{H}$ & $100(6.5)$ & $200(7.5)$ & $200(7.0)$ & $50(6.5)$ & $50(6.5)$ & $100(7.5)$ \\
\hline
\end{tabular}




\begin{tabular}{|c|c|c|c|c|c|c|c|c|}
\hline \multirow{3}{*}{$\begin{array}{l}\text { Compd. } \\
\text { No }\end{array}$} & \multirow[t]{3}{*}{$\mathbf{R}$} & \multirow[t]{3}{*}{$\mathbf{R}^{1 / \mathbf{R}^{2} / \mathbf{R}^{3}}$} & \multicolumn{6}{|c|}{ MIC (zone of inhibition in $\mathrm{mm}$ ) } \\
\hline & & & \multicolumn{3}{|c|}{ Antibacterial activity } & \multicolumn{3}{|c|}{ Antifungal activity } \\
\hline & & & E. coli & S. aureus & P. aurogiosa & Calbican & A.flavus & A. niger \\
\hline 14 & $\mathrm{H}$ & $\mathrm{CH}_{3}$ & $100(8.0)$ & $200(5.5)$ & $200(6.0)$ & $100(8.5)$ & $50(8.0)$ & $100(7.5)$ \\
\hline 15 & $\mathrm{CH}_{3}$ & $\mathrm{H}$ & $100(6.0)$ & $200(5.0)$ & $200(5.5)$ & $50(6.0)$ & $50(7.0)$ & $100(7.0)$ \\
\hline 16 & $\mathrm{CH}_{3}$ & $\mathrm{CH}_{3}$ & $100(6.0)$ & $200(6.5)$ & $200(5.5)$ & $100(8.5)$ & $100(8.0)$ & $100(7.5)$ \\
\hline 17 & $\mathrm{H}$ & - & $100(6.5)$ & $200(6.5)$ & $200(7.5)$ & $100(6.0)$ & $50(6.5)$ & $50(5.8)$ \\
\hline 18 & $\mathrm{CH}_{3}$ & -- & $200(6.6)$ & $200(7.0)$ & $200(7.5)$ & $100(6.5)$ & $100(7.0)$ & $50(5.5)$ \\
\hline 19 & $\mathrm{H}$ & $\mathrm{SO}_{2} \mathrm{NH}_{2}$ & $25(7.5)$ & $25(5.0)$ & $50(5.5)$ & $100(7.5)$ & $50(8.0)$ & $25(6.5)$ \\
\hline 20 & $\mathrm{CH}_{3}$ & $\mathrm{SO}_{2} \mathrm{NH}_{2}$ & $25(6.5)$ & $25(6.5)$ & $25(7.0)$ & $100(6.0)$ & $25(6.5)$ & $50(8.0)$ \\
\hline 21 & $\mathrm{H}$ & $\mathrm{OH}$ & $12.5(7.5)$ & $12.5(6.5)$ & $25(6.5)$ & $50(7.5)$ & $50(6.0)$ & $25(6.5)$ \\
\hline 22 & $\mathrm{CH}_{3}$ & $\mathrm{OH}$ & $25(8.5)$ & $25(8.5)$ & $25(7.5)$ & $50(6.0)$ & $25(6.5)$ & $25(6.5)$ \\
\hline 23 & $\mathrm{H}$ & $\mathrm{H}$ & $50(7.5)$ & $50(5.0)$ & $100(5.5)$ & $25(6.5)$ & $50(8.0)$ & $25(6.5)$ \\
\hline 24 & $\mathrm{H}$ & $\mathrm{NO}_{2}$ & $25(6.5)$ & $25(6.5)$ & $50(7.0)$ & $50(8.0)$ & $50(6.5)$ & $50(8.0)$ \\
\hline 25 & $\mathrm{CH}_{3}$ & $\mathrm{H}$ & $50(8.5)$ & $50(6.5)$ & $100(6.5)$ & $25(6.0)$ & $25(6.0)$ & $50(5.5)$ \\
\hline 26 & $\mathrm{CH}_{3}$ & $\mathrm{NO}_{2}$ & $25(6.0)$ & $25(8.5)$ & $100(7.5)$ & $50(8.5)$ & $50(6.5)$ & $50(7.5)$ \\
\hline \multicolumn{2}{|c|}{ Fluconazole } & & NT & NT & NT & $6.25(9.5)$ & $6.25(9.0)$ & $6.25(8.5)$ \\
\hline \multicolumn{2}{|c|}{ Ciprofloxacin } & & $6.25(9.5)$ & $6.25(9.0)$ & $6.25(8.5)$ & NT & NT & NT \\
\hline
\end{tabular}

NT: denote Not tested, (-) absence of activity

Table 1: Antimicrobial activity data of diversified 2-chloroquinoline derivatives (3-26)

\begin{tabular}{|c|c|c|c|c|c|c|c|c|c|}
\hline $\begin{array}{c}\text { Compd. } \\
\text { No. }\end{array}$ & Mol_Wt & WPSA & volume & $\begin{array}{c}\text { Donor } \\
\text { HB }\end{array}$ & Accpt HB & $\begin{array}{c}\text { QPlogP } \\
\text { o/w }\end{array}$ & PSA & $\begin{array}{c}\text { Rule of } \\
\text { Five }\end{array}$ & $\begin{array}{c}\text { Rule Of } \\
\text { Three }\end{array}$ \\
\hline 3 & 310.742 & 64.226 & 962.235 & 1 & 5 & 3.074 & 73.511 & 0 & 0 \\
\hline 4 & 309.754 & 64.117 & 976.411 & 1 & 3.5 & 4.094 & 60.754 & 0 & 0 \\
\hline 5 & 324.769 & 64.169 & 1022.165 & 1 & 5 & 3.28 & 73.615 & 0 & 0 \\
\hline 6 & 323.781 & 64.223 & 1037.317 & 1 & 3.5 & 4.409 & 60.804 & 0 & 1 \\
\hline 7 & 308.726 & 57.971 & 928.031 & 0 & 5 & 2.927 & 61.591 & 0 & 0 \\
\hline 8 & 322.753 & 57.971 & 989.286 & 0 & 5 & 3.261 & 61.591 & 0 & 0 \\
\hline 9 & 307.738 & 57.533 & 942.958 & 0 & 3.5 & 3.985 & 48.683 & 0 & 0 \\
\hline 10 & 321.765 & 57.533 & 1004.228 & 0 & 3.5 & 4.319 & 48.683 & 0 & 0 \\
\hline 11 & 193.632 & 62.946 & 626.036 & 1 & 2.7 & 2.235 & 33.581 & 0 & 0 \\
\hline 12 & 207.659 & 63.362 & 685.95 & 1 & 2.7 & 2.365 & 33.681 & 0 & 0 \\
\hline 13 & 297.74 & 61.673 & 945.288 & 0 & 3 & 4.103 & 49.534 & 0 & 0 \\
\hline 14 & 311.767 & 60.735 & 1004.841 & 0 & 3 & 4.413 & 49.494 & 0 & 0 \\
\hline 15 & 311.767 & 57.832 & 1003.067 & 0 & 3 & 4.375 & 49.45 & 0 & 0 \\
\hline 16 & 325.794 & 59.574 & 1064.683 & 0 & 3 & 4.727 & 49.527 & 0 & 1 \\
\hline 17 & 212.078 & 131.419 & 646.807 & 0 & 1 & 3.53 & 11.915 & 0 & 0 \\
\hline 18 & 226.105 & 131.228 & 706.306 & 0 & 1 & 3.982 & 11.907 & 0 & 0 \\
\hline 19 & 347.818 & 64.174 & 1020.756 & 3 & 6.5 & 2.201 & 89.075 & 0 & 0 \\
\hline 20 & 361.845 & 64.529 & 1080.092 & 3 & 6.5 & 2.482 & 89.077 & 0 & 0 \\
\hline 21 & 284.744 & 62.903 & 907.097 & 2 & 2.75 & 3.7 & 46.299 & 0 & 0 \\
\hline 22 & 298.771 & 62.742 & 967.929 & 2 & 2.75 & 4.009 & 46.303 & 0 & 0 \\
\hline 23 & 325.815 & 98.236 & 986.45 & 1 & 2.5 & 4.878 & 37.828 & 0 & 1 \\
\hline 24 & 370.812 & 98.186 & 1059.139 & 1 & 3.5 & 4.185 & 82.608 & 0 & 1 \\
\hline 25 & 339.842 & 96.403 & 1046.061 & 1 & 2.5 & 5.169 & 38.381 & 1 & 1 \\
\hline 26 & 384.839 & 97.713 & 1118.581 & 1 & 3.5 & 4.486 & 82.843 & 0 & 1 \\
\hline
\end{tabular}

Table 2: QikProp properties of all the compounds (3-26) calculated from QikProp tool of Schrodinger

The physiochemical properties important for ADME (Absorption, Distribution, Metabolism and Excretion) considerations were predicted using QikProp 3.6 (Schrodinger) that calculates properties like molecular weight, molecular volume, no. of H-bond donors, no. of H-bond acceptors, polar surface area, Q Plog Po/w (Predicted octanol/water partition coefficient) and violations related to Lipinski's "Rule of 5" and Jorgensen's "Rule of 3" to filter out compounds with clear-cut undesirable properties. The prerequisite was to neutralize the compounds before being used by QikProp. The neutralization step was carried out using Lig prep after which all the hits from both the approaches were processed for calculation of ADME properties. 


\section{Results and Discussion}

\section{Chemistry}

The various 2-chloroquinolines were synthesized as per the scheme outlined in Figure 3. Different routes were adopted for the synthesis of target compounds starting from the common intermediates 1 and 2 . The 1,3,4-oxadiazole derivatives (7-10) were synthesized by cyclisation of hydrazones (3-6) of isonicotinic acid hydrazide (INH) or benzoic acid hydrazide with intermediate 1 and 2 using chloramine-T as catalyst in refluxing ethanol. The 2-chloro-3-formylquinoline and 2-chloro-3-formyl-6methylquinoline $(1,2)$ were further reduced to alcohol $(11,12)$ using solid $\mathrm{NaBH}_{4}$ in methanol and subsequent reaction of 11 or 12 with benzoyl or $p$-methyl benzoyl chloride in pyridine affords various benzoate derivatives (13-16). The chlorination of compounds $(11,12)$ with $\mathrm{SOCl}_{2}$ in dry benzene afforded intermediates 3-(chloromethyl)-2-chloroquinoline (17, 18) and their successive nucleophilic substitution reaction with sulphanilamide or $p$-aminophenol in absolute ethanol in the presence of organic base triethylamine (TEA) gave 2-chloroquinolinyl amines (19-22). While various ${ }^{1} \mathrm{H}$-benzimidazol-2-ylsulfanyl)methyl (23-26) derivatives were prepared by reacting intermediate $(17,18)$ with 2-mercaptobenzimidazole or 2-mercapto-6-nitrobenzimidazole in ethanol in presence of base $\mathrm{NaOH}$.

The structure of diverse 2-chloroquinoline derivatives was elucidated by combined use of IR, ${ }^{1} \mathrm{H}$ and ${ }^{13} \mathrm{C}$-NMR and mass spectral data. The presence of the 1,3,4-oxadiazole unit in compounds (7-10) was supported by the appearance of two quaternary signals of (C-2, C-5) at $\delta$ value 164.5 and $166.7 \mathrm{ppm}$ in ${ }^{13} \mathrm{C}$-NMR spectrum of compound 7 . This was further supported by mass spectrum of compound $7(\mathrm{~m} / \mathrm{z}$ 309.12). The synthesis of compounds (13-16) was achieved by reacting quinoline carbinol derivatives (11, 12) with benzoyl chloride in pyridine. The formation of benzoate derivatives were established by locating characteristics peak of $-\mathrm{CH}_{2} \mathrm{OCO}$ - which was observed in the range at $\delta$ value 5.01-5.06 ppm integrating for two protons in ${ }^{1} \mathrm{H}-\mathrm{NMR}$. In ${ }^{13} \mathrm{C}-\mathrm{NMR}$ this particular function was observed at $\delta$ value $64.6 \mathrm{ppm}$ for compound 13 . In IR spectra the characteristics $\mathrm{C}=\mathrm{O}$ and $\mathrm{C}-\mathrm{O}$ band for compounds (13-16) were observed at $1724-1730$ and $1117-1123 \mathrm{~cm}^{-1}$ respectively. The synthesis of secondary amines (19-22) of sulphanilamide/ $p$-aminophenol was identified by locating $-\mathrm{CH}_{2} \mathrm{NH}$ - function in spectral data. The ${ }^{1} \mathrm{H}-\mathrm{NMR}$ signal due methylene of $-\mathrm{CH}_{2} \mathrm{NH}$ - was observed at $\delta$ value $4.59-4.62 \mathrm{ppm}$, while the $\mathrm{NH}$ proton was resonated at 4.30-4.38 ppm as singlet or broad singlet. The synthesis was further confirmed by mass spectrometry in which molecular ion peak was registered at $\mathrm{m} / \mathrm{z} 347.11\left(\mathrm{M}^{+}\right)$ and $\mathrm{M}+2$ peak at 349.11 for compound 20. The synthesis of compounds (23-26) was established by identifying the characteristics $-\mathrm{CH}_{2} \mathrm{~S}$ - peak in NMR. In ${ }^{1} \mathrm{H}-\mathrm{NMR}$ spectra of compounds (23-26) the signal due methylene proton of - $\mathrm{CH}_{2} \mathrm{~S}$ - group was resonated at $\delta$ value 4.69-4.72 integrating for two protons. While in ${ }^{13} \mathrm{C}-\mathrm{NMR}$, the methylene carbon was identified at $\delta 38.0$ for compound 23. All these observations confirm successful synthesis of compounds.

\section{Antimicrobial activity}

The diversified 2-chloroquinoline derivatives were tested for their antibacterial activity against gram positive and gram negative bacterial strains viz. Escherichia coli NCTC 10418, Staphylococcus aureus NCTC 65710, Pseudomonas aeruginosa NCTC 10662 and antifungal activity against three fungal strains viz. C albican, A. flavus, A. niger using cup-plate method at conc. range of 6.25, 12.5, $25,50,100,200$ and $400 \mu \mathrm{g} / \mathrm{ml}[28,29]$.

\section{Antibacterial activity}

Results of antibacterial screening are presented in Table 1 as MIC the conc. at which no visible growth was observed (zone of inhibition in $\mathrm{mm}$ ). The quinolinyl hydrazones (3-6) and there corresponding oxadiazoles (7-10) exhibited variable effect on the growth of bacterial strains. The hydrazones and oxadiazoles of INH, compounds $(3,5,7$ and 8$)$ exhibited MIC of 12.5 to $50 \mu \mathrm{g} /$ $\mathrm{ml}$ against test strains and among these compound 7 and 8 showed MIC of $12.5 \mu \mathrm{g} / \mathrm{ml}$ against the E. coli. While hydrazones and oxadiazoles of benzoic acid hydrazide (4, 6, 9 and 10) showed MIC in the range of 50 to $200 \mu \mathrm{g} / \mathrm{ml}$. The difference in the MIC within these analogues (3-10) may be attributed to presence of INH residue which itself is a potent antimycobacterial agent. The intermediate compound 11 and 12 showed moderate antibacterial (MIC 50 to $100 \mu \mathrm{g} / \mathrm{ml}$ ) activity and their corresponding ester (13-16) turns from moderately active to weakly active (MIC 100 to $200 \mu \mathrm{g} / \mathrm{ml}$ ). The chloromethyl intermediate (17 and 18) were also showed weak activity which was observed at (MIC $200 \mu \mathrm{g} / \mathrm{ml}$ ) against the test bacterial strains. While their corresponding secondary amines of sulphanilamide $(19,20)$ and $p$-aminophenol $(21,22)$ was comparatively more active in inhibiting the growth of the bacteria (MIC 12.5 to $25 \mu \mathrm{g} / \mathrm{ml}$ ). Among the 2-mercaptobenzimidazole derivatives (23-26), the nitro derivatives were more active against the all the bacterial strains and there MIC was observed in the range of $25-50 \mu \mathrm{g} / \mathrm{ml}$.

\section{Antifungal activity}

The antifungal activity quinolinyl hydrazones (3-6) and there corresponding oxadiazoles (7-10) derivatives was found to be weak as their MIC were observed in the range of 100 to $200 \mu \mathrm{g} / \mathrm{ml}$ against test strains. The compound 11 and 12 also exhibited weak antifungal activity while there ester analogue (13-16) were slightly more active than the parent compound and there MIC were observed in between 50 to $100 \mu \mathrm{g} / \mathrm{ml}$. The antifungal activity of chloromethyl derivatives of 2-chloroquinoline (17 and 18) was found in the range of 50 to $100 \mu \mathrm{g} / \mathrm{ml}$. The quinolinyl amine derivatives of sulphanilamide and $p$-amniophenol (19-22) showed antifungal activity in the range of $25-100 \mu \mathrm{g} / \mathrm{ml}$. The benzimidazole derivatives (23-26) showed moderate antifungal activity against the test strain C. albicans, A. niger and A. flavus was and there MIC observed at 25 to $50 \mu \mathrm{g} / \mathrm{ml}$. 


\section{Computational Studies}

To understand the mechanism of action underlying activity of most active compound 21, we proceeded to examine the interaction of compound 21 with bacterial DNA gyrase (PDB code: 3G75) [30]. All docking runs were carried out as per Glide XP Docking protocol in Schrodinger 9.4 [31,32]. The XP Glide score obtained for compound 21 was found to be -7.62. Figure 4 and Figure 5 shows the binding mode of compound 21 interacting with DNA gyrase and revealed that amino acids ASP57, GLU58, ASH81,ILE51, ILE175, VAL79, ILE102, ILE86 and PRO87 located in the binding pocket played vital roles in the interaction of compound 21 with the enzyme. The hydroxyl substituent at the distal phenyl ring and $\mathrm{NH}$ group acts as $\mathrm{H}$-bond donar and formed $\mathrm{H}$-bond network with the amino acid residue ASP57 and GLU58 at 1.57 and $2.01 \AA$ respectively.One nitrogen atom of quinoline nucleus providedadditional H-bond with ASH81 at $1.32 \AA$. The hydrophobic interactions with ILE51, ILE175, VAL79, ILE102, ILE86 and PRO87 further stabilized the compound in the active site of bacterial DNA gyrase.

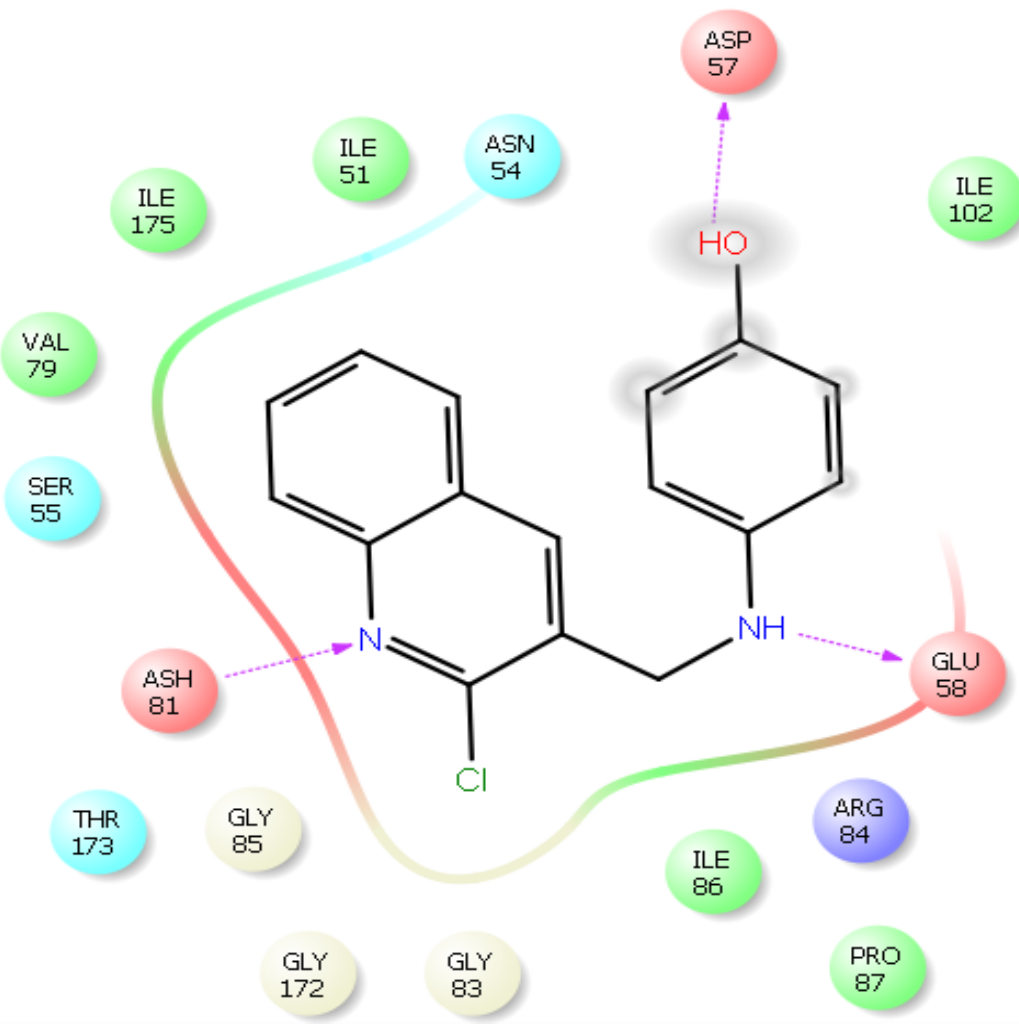

Figures 4: 2-Dimentional (2D) diagram showing hydrogen bonding interaction of compound 21 with active sites of enzyme DNA gyrase (PDB ID 3G75)

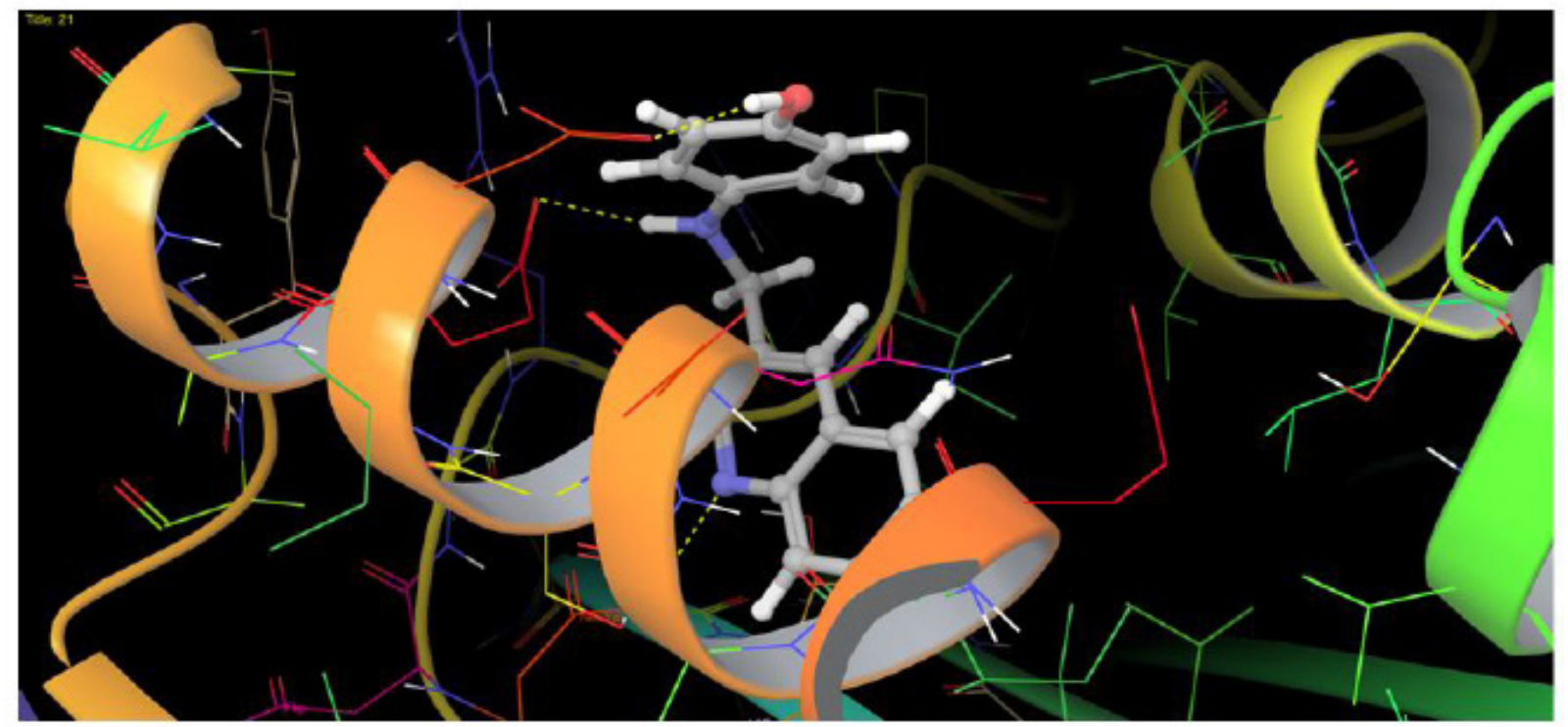

Figures 5: 3-Dimentional (3D) diagram showing hydrogen bonding interaction of compound 21 with active sites of enzyme DNA gyrase (PDB ID 3G75) 
The ADME (Absorption, Distribution, Metabolism and Excretion) properties are crucial determinants for the successful development of new drugs. Unfavorable ADME properties can lead to rejection of a drug in the later stages of drug process [33]. All the compounds synthesized, were further processed for ADME, Lipinski's "Rule of 5" and Jorgensen's "Rule of 3" using QikProp tool of Schrodinger which is built using experimental details of 710 compounds including 500 drugs and heterocyclic compounds. The QikProp properties obtained for all the compounds are listed in Table 2 [34]. QikProp calculates properties like molecular weight, molecular volume, no. of H-bond donors, no. of $\mathrm{H}$-bond acceptors, polar surface area, QPlogPo/w (Predicted octanol/water partition coefficient) and violations related to Lipinski's "Rule of 5" [35] and Jorgensen's "Rule of 3" [36] to filter out compounds with clear-cut undesirable properties. Compounds that satisfy Lipinski's "Rule of 5" are considered drug-like and compounds with fewer (and preferably no) violations of Jorgensen's "rule of 3", are more likely to be orally available. All the compounds showed excellent ADME properties and passed Lipinski's "Rule of 5" having no violations. In addition, all compounds except 6, 16, 23-26 also passed Jorgensen's "rule of 3", which showed that they have potential of $100 \%$ orally bioavailable. The excellent ADME property of these hits makes them promising candidates for future development as antimicrobial agents.

\section{Conclusion}

Impelled by the diverse potential of quinoline derivatives, a series of diversified 2-chloroquinoline derivatives was synthesized and evaluated for antibacterial and antifungal activity. Among the screened derivatives, compound 21 (4-((2-Chloroquinolin-3yl)methylamino)phenol) was found to be the most potent antibacterial ligand having the MIC of $12.5 \mu \mathrm{g} / \mathrm{ml}$ against E. coli and S. aureus. Against $P$. auroginosa the MIC was found to be $25 \mu \mathrm{g} / \mathrm{ml}$. Molecular docking studies were also performed to further investigated the interaction of ligand 21 with active sites of bacterial DNA gyrase (PDB ID 3G75). The XP glide docking simulation studies exhibited that compound 21 forms three hydrogen bonds with the residue ASP 57, GLU58, ASH 81. The in-vitro studies coupled with computational studies suggest that compound 21 is promising candidate for further exploitation as lead molecules against bacterial infection.

\section{Acknowledgment}

The authors are to Jamia Hamdard for providing necessary facility. Thanks are due to IIT Delhi and CDRI, Lucknow, for recording spectral data.

\section{References}

1. Mishra SK, Rijal PB, Pokhrel BM (2013) Emerging threat of multidrug resistant bugs--Acinetobacter calcoaceticus baumannii complex and methicillin resistant Staphylococcus aureus. BMC Res Notes 6:98.

2. Cetinkaya Y, Falk P, Mayhall CG (2000) Vancomycin-resistant enterococci. Clin Microbiol Rev 13: 686-707.

3. Rex JH, Rinaldi MG, Pfaller MA (1995) Resistance of Candida species to fluconazole. Antimicrob Agents Chemother 39: 1-8.

4. Deresinski S (2005) Methicillin-Resistant Staphylococcus aureus: An Evolutionary, Epidemiologic, and Therapeutic Odyssey. Clin Infect Dis 40: 562-73.

5. Gulshan K, Moye-Rowley WS (2007) Multidrug Resistance in Fungi. Eukaryot Cell 06: 1933-42.

6. O’Connell D (2006) Evolving virulence. Nat Rev Microbiol 4: 83.

7. Davies J, Davies D (2010) Origins and evolution of antibiotic resistance. Microbiol Mol Biol Rev 74: 417-33.

8. Aminov RI, Mackie RI (2007) Evolution and ecology of antibiotic resistance genes. FEMS Microbiol Lett 271: 147-61.

9. Moellering RC (2011) Discovering new antimicrobial agents. Int J Antimicrob Agents 37: 2-9.

10. Spellberg B, Powers JH, Brass EP, Miller LG, Edwards JE (2004) Trends in antimicrobial drug development: implications for the future. Clin Infect Dis 38: $1279-86$.

11. Wenzel RP, Edmond MB (2000) Managing Antibiotic Resistance. N Engl J Med 343: 1961-3.

12. Rolston KV (2009) New antimicrobial agents for the treatment of bacterial infections in cancer patients. Hematol Oncol 27: 107-14.

13. Abbanat D, Morrow B, Bush K (2008) New agents in development for the treatment of bacterial infections. Curr Opinion Pharmacol 8: 582-92.

14. dos Santos JL, Dutra LA, Ferreira de Melo TR, Chin CM (2012) New Antitubercular Drugs Designed by Molecular Modification, Understanding TuberculosisNew Approaches to Fighting Against Drug Resistance. InTech 169-86.

15. Butler MS, Blaskovich MA, Cooper MA (2013) Antibiotics in the clinical pipeline in 2013. J Antibiot 66: 571-91.

16. Kumar S, Bawa S, Gupta H (2009) Biological activities of quinoline derivatives. Mini Rev Med Chem 09: 1648-54.

17. Diacon AH, Pym A, Grobusch M, Patientia R, Rustomjee R, et al. (2009) The Diarylquinoline TMC207 for Multidrug-Resistant Tuberculosis. N Engl J Med 360: 2397-405.

18. Haggiag S, Ruggieri S, Gasperini C (2013) Efficacy and safety of laquinimod in multiple sclerosis: current status. Ther Adv Neurol Disord 6: 343-52.

19. Bax BD, Chan PF, Eggleston DS, Fosberry A, Gentry DR, et al. (2010) Type IIA topoisomerase inhibition by a new class of antibacterial agents. Nature 466: $935-40$.

20. Emami S, Foroumadi A, Samadi N, Faramarzi MA, Rajabalian S (2009) Conformationally Constrained Analogs of N-Substituted Piperazinylquinolones: Synthesis and Antibacterial Activity of N-(2,3-Dihydro-4-hydroxyimino-4H-1-benzopyran-3-yl)-piperazinylquinolones. Arch Pharm (Weinheim) 342: 405-11.

21. Thumar NJ, Patel MP (2011) Synthesis and antimicrobial activity of some new N-substituted quinoline derivatives of 1H-pyrazole. Arch Pharm (Weinheim) 344: $91-101$.

22. Kumar S, Bawa S, Kaushik D, Panda BP (2011) Synthesis and In-vitro Antimicrobial Activity of Secondary and Tertiary Amines Containing 2-Chloro-6-methylquinoline Moiety. Arch Pharm (Weinheim) 344: 474-80.

23. Kumar S, Bawa S, Drabu S, Panda BP (2011) Design and synthesis of 2-chloroquinoline derivatives as non-azoles antimycotic agents. Med Chem Res 20: 1340-8. 
24. Bawa S, Kumar S (2009) Synthesis of Schiff's bases of 8-methyl-tetrazolo[1,5-a]quinoline as potential anti-inflammatory and antimicrobial agents. Indian J Chem 48B: 142-5.

25. Meth-Cohn O, Narine B, Tarnowski B (1981) A versatile new synthesis of quinolines, thienopyridines and related fused pyridines 5: The synthesis of 2-chloroquinoline-3-carbaldehydes. J Chem Soc Perkin Trans 1: 1531-6.

26. Khan MSY, Chawla G, Mueed MA (2004) Synthesis characterization and biological evaluation of substituted oxadiazole, and triazole derivatives. Indian J Chem 43B: $1302-5$.

27. Brandstrom AE, Lamm BR (1986) Gastric acid secretion inhibitor intermediates. US 4620008.

28. Kumar S, Bawa S, Drabu S, Gupta H, Machwal L, et al. (2011) Synthesis, antidepressant and antifungal evaluation of novel 2-chloro-8-methylquinoline amine derivatives. Eur J Med Chem 46: 670-5.

29. Barry AL (1976) The antimicrobial susceptibility test: Principle and Practice, Illus Lea and Febiger, Philadelphia, 1976, $180 ;$ Biol. Abstr. 64 (1977) 25183.

30. Ronkin SM, Badia M, Bellon S, Grillot AL, Gross CH, et al. (2010) Discovery of pyrazolthiazoles as novel and potent inhibitors of bacterial gyrase. Bioorg Med Chem Lett 20: 2828-31

31. Friesner RA, Murphy RB, Repasky MP, Frye LL, Greenwood JR, et al. (2006) Extra precision glide: docking and scoring incorporating a model of hydrophobic enclosure for protein-ligand complexes. J Med Chem 49: 6177-96.

32. Maestro, Version 9.4, Schrödinger, LLC, New York, NY, 2013.

33. Hughes JP, Rees S, Kalindjian SB, Philpott KL (2011) Principles of early drug discovery. Br J Pharmacol 162: 1239-49.

34. QikProp, version 3.6, Schrödinger, LLC, New York, NY, 2013.

35. Lipinski CA, Lombardo F, Dominy BW, Feeney PJ (2001) Experimental and computational approaches to estimate solubility and permeability in drug discovery and development settings. Adv Drug Delivery Rev 46: 3-26.

36. Duffy EM, Jorgensen WL (2000) Prediction of Properties from Simulations: Free Energies of Solvation in Hexadecane, Octanol, and Water. J Am Chem Soc 122: $2878-88$. 